\title{
Modern management of oesophageal varices
}

\author{
P J Gow, R W Chapman
}

\begin{abstract}
Haemorrhage from oesophageal varices is a life threatening emergency with a mortality rate in the order of $30 \%-50 \%$. In the last three decades there have been many advances in the treatment and prevention of variceal bleeding. Over recent years the introduction of new pharmaceutical agents that reduce portal pressure, endoscopic variceal ligation, transjugular intrahepatic portosystemic shunt, and the availability of liver transplantation have further increased the therapeutic options available to the physician treating this disorder. This article reviews the literature regarding therapies available in the treatment of haemorrhage from oesophageal varices and provides guidelines to aid the physicians in clinical decision making. (Postgrad Med F 2001;77:75-81)
\end{abstract}

Keywords: oesophageal varices; portal hypertension; transjugular intrahepatic portosystemic shunt (TIPS); liver transplantation

Even in the year 2001 haemorrhage from oesophageal varices remains a major medical emergency with a high mortality rate. Over recent years, however, the introduction of new pharmaceutical agents that reduce portal pressure, endoscopic variceal ligation, transjugular intrahepatic portosystemic shunt (TIPS), and the availability of liver transplantation have further increased the therapeutic options in the treatment of oesophageal varices. The variety of treatment options has resulted in an explosion of literature dealing with oesophageal varices. Despite the increasing volume of clinical trails and laboratory research, therapeutic decision making concerning patients with variceal haemorrhage is often still difficult. Managing oesophageal varices at the start of the 21 st century still poses considerable challenges to both the general internist and hepatologist.

Pathophysiology of portal hypertension The initiating factor in the development of portal hypertension is increased resistance to portal flow. In the Western world cirrhosis is the most common cause, and the major site of resistance to flow is the hepatic sinusoid (table 1). Stellate cells line the perisinusoidal space and are transformed into contractile myofibroblasts in response to liver injury. These cells play a central part in the development of hepatic fibrosis. Stellate cells regulate sinusoidal resistance and flow in response to vasoactive substances, especially endothelin ${ }^{1}$ and nitric oxide. ${ }^{2}$ Sinusoidal resistance exerts the "backward" component of portal hypertension. The "forward" component is the
Table 1 Causes of portal hypertension classified according to the site of increased vascular resistance (From: Oxford Textbook of Medicine)

\author{
Suprahepatic \\ Constrictive pericarditis \\ Right heart failure \\ Inferior vena cava thrombosis \\ Budd-Chiari syndrome \\ Veno-occlusive disease \\ Intrahepatic \\ Presinusoidal \\ Schistosomiasis \\ Primary biliary cirrhosis (early stage) \\ Sarcoid \\ Myeloproliferative diseases \\ Nodular regenerative hyperplasia \\ Sinusoidal \\ Cirrhosis \\ Chronic active hepatitis \\ Alcoholic hepatitis and fatty liver \\ Infrahepatic \\ Portal vein thrombosis \\ Splenic vein thrombosis \\ Increased hepatic blood flow \\ Hepatoportal arteriovenous fistula \\ Conditions associated with massive splenomegaly
}

increased splanchnic blood flow that accompanies the vasodilated circulation in cirrhosis. It has been demonstrated that the main site of low systemic vascular resistance is the splanchnic circulation. ${ }^{3}$

Haemodynamic studies have provided great insight into understanding the pathophysiology of portal hypertension and the development of oesophageal varices. It is difficult to directly measure the portal pressure gradient (the difference between portal pressure and inferior vena cava pressure) due to the inaccessibility of the portal vein to catheter placement. To overcome this obstacle an indirect measurement of portal pressure gradient can be obtained with the hepatic venous pressure gradient (HVPG). The HVPG reflects the difference between wedged and free hepatic venous pressure and closely reflects the portal pressure gradient in patients with cirrhotic portal hypertension. Normal HVPG is $\leqslant 4 \mathrm{~mm} \mathrm{Hg}$, it is not until the HVPG is above $10 \mathrm{~mm} \mathrm{Hg}$ that oesophageal varices develop. However, not all patients with HVPG above this level have oesophageal varices. Once varices have developed they tend to steadily increase in size before they eventually rupture and bleed. There is little information regarding the rate of development of varices in patients with cirrhosis. In one large study approximately $8 \%$ of patients with cirrhosis developed varices per year. ${ }^{4}$ In addition, in $10 \%-20 \%$ of patients with small varices they increase to large in the year after the first detection. ${ }^{56}$ With this information a rational screening programme would involve second yearly endoscopy in patients without varices, and annual endoscopy in patients with small varices to detect patients at high risk of bleeding.

Although approximately $90 \%$ of patients with cirrhosis will develop varices ${ }^{4}{ }^{6}$ bleeding
Submitted 29 March 2000 Accepted 4 July 2000 
Box 1: Factors associated with high risk of first variceal haemorrhage

- $\mathrm{HVPG}>12 \mathrm{~mm} \mathrm{Hg}$

- Red sign, red wale mark on varix

- Child class

- Continued alcohol abuse

- Varix size

occurs in only $25 \%-35 \%$ of patients. ${ }^{78}$ Mortality from a first bleed is approximately $50 \%$, the risk of recurrent bleeding is in the order of $70 \%$ with an associated inpatient mortality rate of $30 \% .^{49}$ Most deaths occur after early rebleeding, which occurs in up to $50 \%$ of patients within the first week. ${ }^{70}$ The risk of rebleeding and death remains elevated for the first six weeks after an initial bleed and then rapidly decreases. ${ }^{9}$ The degree of hepatic decompensation (Child class) is the most important determinant of long term survival after a variceal haemorrhage. ${ }^{11} 12$

As not all patients with cirrhosis will develop varices and not all patients with varices will bleed it is essential to be able to predict patients at high risk of bleeding so as to best target preventative therapy (box 1). Patients with a HVPG of less than $12 \mathrm{~mm} \mathrm{Hg}$ do not bleed from varices. ${ }^{13} 14$ There is, however, no clear relationship between HVPG above $12 \mathrm{~mm} \mathrm{Hg}$ and risk of bleeding. Variceal size is also a factor. Patients with large varices have a $20 \%$ to $30 \%$ annual incidence of bleeding compared with $10 \%$ to $15 \%$ in unselected patients with cirrhosis and varices. ${ }^{15} 16$ This has been confirmed in a large prospective study. ${ }^{7}$ Red sign and red wale marking on the variceal wall also indicate an increased risk of bleeding. ${ }^{77}$ Additional risk factors include severity of liver disease and continued alcohol abuse. ${ }^{717}$

\section{Prevention of first bleed}

$\beta$-BLOCKERS AS PRIMARY PREVENTION (BOX 2)

Although a large number of drugs have been demonstrated to lower portal pressure, extensive clinical experience has only been gained with the use of non-selective $\beta$-blockers. Eighty mg of propranolol daily has been demonstrated to lower HVPG by $13 \%{ }^{18}$ This reduction in HVPG has been demonstrated to continue during long term therapy. ${ }^{18}$ The usefulness of $\beta$-blockers as primary prophylaxis has been investigated in a large number of randomised prospective trials. ${ }^{19-25}$ The vast majority of these trials conclude that $\beta$-blockers lead to significantly fewer episodes of variceal haemorrhage in comparison with placebo. Yet only one study demonstrated a significant improvement in survival with $\beta$-blockers. ${ }^{19}$ The benefit of $\beta$-blockers as primary prophylaxis becomes more pronounced when high risk patients are specifically included; namely HVPG $>12 \mathrm{~mm}$ $\mathrm{Hg}$ and large varices. ${ }^{23}$

Several meta-analyses have addressed the effect of $\beta$-blockers as primary prophylaxis. ${ }^{16262728}$ All have shown a significant reduction in the incidence of first variceal haemorrhage, but none have displayed a significant effect on survival. Failure to detect a
Box 2: Role Of $\beta$-blockers in

prevention of first bleed

- Should definitely be used in all patients with "high risk" varices

- Reduce incidence of first bleed compared with placebo

- Treatment should be lifelong once initiated

- In those who experience side effects from $\beta$-blockers, nitrates should be used

survival advantage with $\beta$-blockers probably reflects a type II error; more patients need to be included in such studies to show an effect on mortality.

No mortality from treatment has been reported. It could be argued that $\beta$-blockers should be used as primary prevention in all patients with oesophageal varices. There is no doubt, however, that they are indicated in all patients who are at high risk of variceal haemorrhage (box 1), unless there is a specific contraindication. As there is evidence that stopping treatment may precipitate a bleed, ${ }^{29}$ treatment once initiated, should be lifelong.

\section{SCLEROTHERAPY AS PRIMARY PREVENTION}

More than 20 trials have studied this issue enrolling in excess of 1000 patients. ${ }^{30}$ The trial protocols were extremely heterogeneous, variceal size varied considerably, and only one required a HVPG of greater than $12 \mathrm{~mm} \mathrm{Hg}$. Sclerotherapy technique also varied, with a variety of sclerosants in different doses injected intravariceally or perivariceally or both. Although some early trials showed a reduction in bleeding in the sclerotherapy group more recent and larger trials have shown either no value or a deleterious effect of sclerotherapy. ${ }^{31}$ Endoscopic sclerotherapy is therefore not indicated for the prevention of first variceal haemorrhage in cirrhotic patients.

Recent trials into the use of variceal ligation in the prevention of the first episode of variceal bleeding are just being completed. In one study of patients with large varices, ligation therapy significantly reduced the incidence of variceal haemorrhage compared with propranolol. In this study, however, approximately half the patients had non-cirrhotic portal hypertension and no difference in mortality was demonstrated. ${ }^{32}$ A second study used no treatment in the control group and reported a significant reduction in prevention of bleeding and death with variceal ligation. The preliminary results concerning the use of variceal ligation as primary prevention appear promising. The results of further trials confirming these results are still needed.

\section{OTHER MEASURES AS PRIMARY PREVENTION}

(BOX 3)

Nitrates may be as effective as $\beta$-blockers for primary prophylaxis and offer an alternative to patients who are intolerant of $\beta$-blockers. Isosorbide mononitrate has been compared to propranolol in one study. ${ }^{33}$ There was a slight 
Box 3: Role of other measures in prevention of first bleed

- No indication for prophylactic sclerotherapy

- Newer evidence suggests that variceal ligation may be more effective and safer

- Nitrates can be used in patients in whom $\beta$-blockers are contraindicated

surplus of haemorrhagic events with the nitrate group; the majority of patients, however, remained without haemorrhage.

There have been several studies examining the combination of $\beta$-blockers and nitrates in reducing portal pressure gradient. This combination of therapy appears move effective in reducing pressure than $\beta$-blockers alone. There are very few studies which examine the role of this combination as primary prevention. One study which enrolled only well compensated cirrhotics revealed significantly less variceal bleeding in the combination group compared with $\beta$-blockers alone, but no effect on mortality. ${ }^{34}$ Recently results from a seven year follow up of this study have been published and report findings results to the original; namely a reduction in variceal bleeding but no difference in mortality. ${ }^{35}$ Currently there is too little clinical evidence to make strong recommendations about the use of $\beta$-blockers in addition to nitrates as primary prevention.

Four studies have demonstrated that shunt surgery is very effective in preventing variceal bleeding, ${ }^{36-39}$ however, this was at the cost of an increased incidence of encephalopathy and reduced survival.

The role of TIPS in the prevention of first variceal haemorrhage, surprisingly, has not been examined. TIPS is unlikely, however, to play an important part in the primary prevention of variceal haemorrhage due to the high incidence of encephalopathy that complicates this procedure.

\section{Treatment of acute variceal haemorrhage (box 4)}

GENERAL MANAGEMENT

In managing patients with acute variceal haemorrhage the involvement of experienced medical staff from the outset is essential. Large bore intravenous access is necessary to allow rapid transfusion if required. Initial fluid resuscitation should be titrated to restore the systolic blood pressure to 80 or $90 \mathrm{~mm} \mathrm{Hg}$, further fluid requirements should aim to maintain haemoglobin at $100 \mathrm{~g} / 1$ and urine output above $30 \mathrm{ml} /$ hour. Overly aggressive fluid replacement should be avoided as overfilling may increase portal pressure leading to rebleeding.

Pulmonary aspiration of blood or gastic secretions is common due to the combination of encephalopathy and impaired consciousness due to shock. In patients with significantly reduced conscious state early endotracheal intubation is mandatory.

Bacterial infection complicates variceal haemorrhage in cirrhosis in up to $66 \%$ of patients. ${ }^{40-42}$ A recent meta-analysis has demonstrated that short term prophylactic antibiotics significantly reduces the incidence of infection and increases short term survival. ${ }^{43}$ Prophylactic antibiotics therefore, should be routinely used in all patients for seven days after admission for variceal haemorrhage.

\section{ENDOSCOPIC MANAGEMENT}

Urgent endoscopy plays a crucial role in the management of all patients with variceal bleeding. It allows confirmation as to the cause of bleeding in addition to allowing specific therapy to be initiated. It is a point worth emphasising that variceal haemorrhage is not the only cause of upper gastrointestinal bleeding in cirrhotic patients. The incidence of pep-

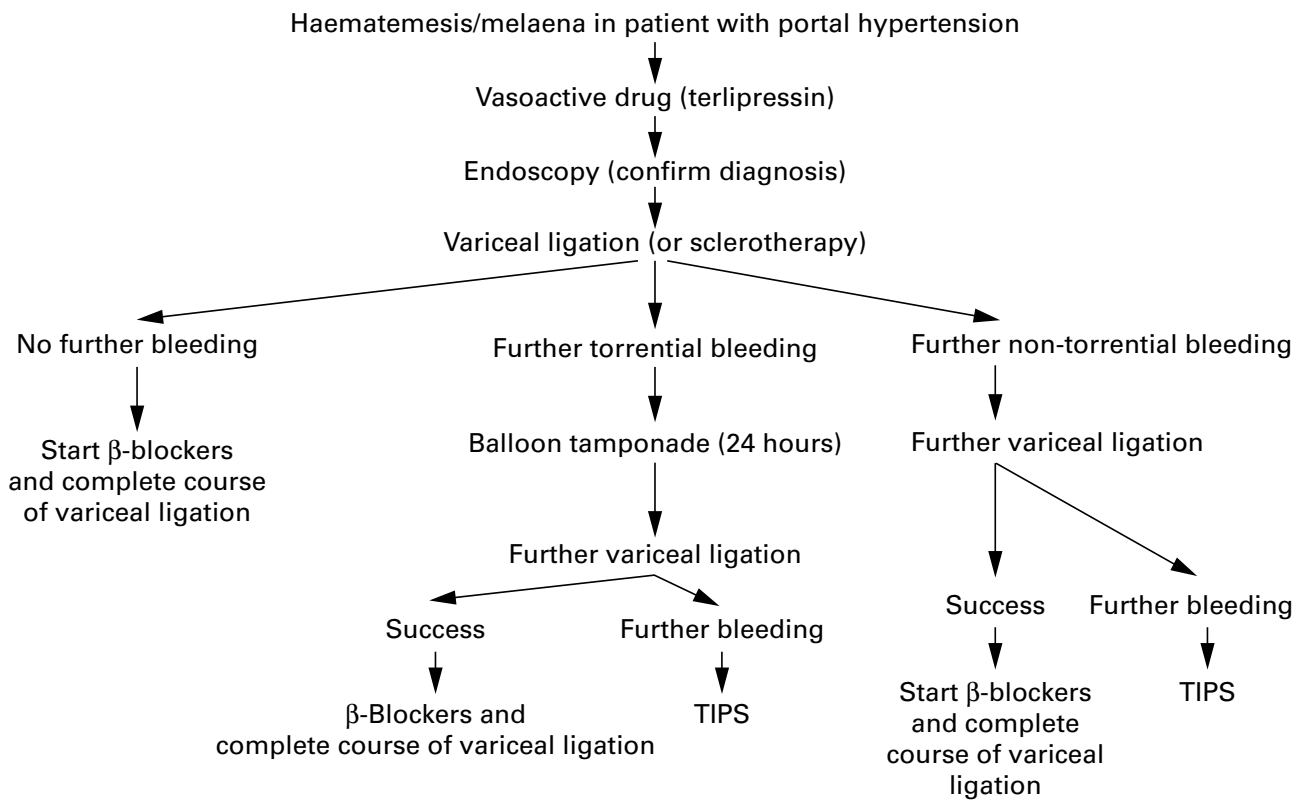

Figure 1 Suggested practice protocol for the management of bleeding oesophageal varices. In all patients with bleeding from oesophageal varices liver transplantation should be considered. 
Box 4: Treatment of acute variceal haemorrhage

- Titrate fluid resuscitation to a systolic blood pressure of $80-90 \mathrm{~mm} \mathrm{Hg}$ only

- Endotracheal intubation in patients with grade III-IV encephalopathy to protect airway

- Prophylactic antibiotics increases short term survival in cirrhotic patients with acute variceal haemorrhage

- Terlipressin, somatostatin, and octreotide control bleeding in approximately $80 \%-90 \%$

- Variceal ligation appears to be equally as effective as sclerotherapy in controlling acute variceal haemorrhage

- Balloon tamponade has a high complication rate, its use should be restricted to patients with massive bleeding not controlled by initial therapy

- TIPS is the treatment of choice in patients unresponsive to endoscopic management

tic ulceration is increased in cirrhosis, ${ }^{44}$ bleeding may be directly from portal hypertensive gastropathy and gastric or duodenal varices may be also bleed. These different pathologies require alternative therapies than would be routinely employed in haemorrhage from oesophageal varices.

Sclerotherapy is still widely used as first choice in endoscopic treatment because it controls haemorrhage in $80 \%-90 \%$ of cases. $^{45}$ Minor complications such as pain, fever, and transient dysphagia are common. In addition, mucosal ulceration develops in up to $80 \%$ of patients ${ }^{43}$ and may cause rebleeding in $20 \%$ of patients. ${ }^{46}{ }^{47}$ Differences in the site of injection (intravariceal or perivariceal or both), type, or volume of sclerosant do not appear to appreciably influence the efficacy of the treatment.

Variceal ligation appears to be as equally effective as sclerotherapy in controlling acute variceal haemorrhage. ${ }^{48-52}$ The choice between the two procedures primarily depends on operator experience, although variceal ligation is associated with fewer side effects.

PHARMACOLOGICAL MANAGEMENT

A number of drugs have been used in the treatment of acute variceal bleeding in an attempt to induce haemostasis while endoscopic therapy is arranged, in addition to reducing the risk of early rebleeding.

Vasopressin is the oldest of these drugs and was first introduced into clinical practice in the 1950s. Vasopressin induces splanchnic vasoconstriction and thereby reduces portal pressure. Side effects with the use of this drug are unfortunately common. In particular vasopressin induces systemic vasoconstriction, reducing cardiac output and myocardial blood flow, potentially resulting in myocardial ischaemia, myocardial infarction, arrhythmias, and cerebrovascular accidents. For these reasons vasopressin should not be routinely used in acute variceal haemorrhage as there are far safer drugs available.

Terlipressin (Glypressin) is a synthetic analogue of vasopressin, with a prolonged half life of 3-4 hours. This enables the drug to be given as bolus intravenous injections. Terlipressin controls bleeding in $80 \%$ of cases and is the only pharmacological agent that has been shown to reduce mortality from variceal bleeding. ${ }^{53}$ Terlipressin is superior to vasopressin (with or without nitroglycerine) in controlling bleeding. ${ }^{54-56}$ In addition side effects are less common. $^{57}$

Somatostatin has similar efficacy in controlling bleeding as terlipressin. ${ }^{58}$ As it has a short half life (2-3 min) it needs to be given by infusion. Studies comparing somatostatin with terlipressin reveal similar efficacy in controlling bleeding, and significantly fewer side effects than with the use of terlipressin. ${ }^{59}$

Octreotide is a synthetic longer acting analogue of somatostatin. Octreotide is a much newer drug and thus has been less extensively investigated. Control of bleeding appears to be similar to that seen with terlipressin and somatostatin. ${ }^{60}$

Pharmacological therapy has an established role in the management of the acute variceal haemorrhage. Several drugs including terlipressin, vasopressin plus nitroglycerine, somatostatin, and octreotide have been shown to be effective. The decision regarding the best pharmacological therapy has currently not been resolved, but vasopressin is best avoided due to the high incidence of side effects.

\section{BALLOON TAMPONADE}

Balloon tamponade is aimed at obtaining temporary haemostasis by direct compression of varices at the oesophagogastric junction. Efficacy in controlling bleeding is highly variable, ranging from $40 \%-90 \% .{ }^{61-63}$ Rebleeding occurs in $50 \%$ of patients within 24 hours of balloon deflation. ${ }^{63}$ Placement of the balloon is associated with an unacceptable death rate of $6 \%-20 \%$ due primarily to oesophageal perforation and pulmonary aspiration. ${ }^{6164}$ Due to the high incidence of complications associated with balloon placement it is prudent for the patient to be intubated and sedated before balloon insertion to minimise potential risks. Inflation of the gastric balloon followed by continual gentle pressure on the apparatus is usually adequate to control bleeding from oesophageal varices. After 24 hours the balloon should be deflated due to the risk of mucosal ulceration. It is rarely necessary to inflate the oesophageal balloon. Due to its high complication rate there is no indication for the routine use of balloon tamponade in the first line management of acute bleeding. Its use should be restricted to patients with massive bleeding not controlled by initial therapy while definitive treatment is arranged.

TIPS

This radiological intervention creates an intrahepatic shunt by placing a stent connecting the hepatic and portal veins. TIPS is now widely used as rescue therapy in patients unresponsive 
Box 5: prevention of rebleeding

- $\beta$-Blockers indicated in all patients after variceal bleed

- Overall $\beta$-blockers reduce the risk of rebleeding by about $40 \%$ and mortality by $20 \%$

- Reduced incidence of rebleeding and death if $\beta$-blockers combined with endoscopic eradication of varices

- Variceal ligation requires fewer sessions to obliterate varices and results in fewer complications compared with sclerotherapy

- Sclerotherapy may be necessary after successful ligation therapy to eradicate small residual varices and prevent recurrence of varices

to endoscopic management and is the accepted procedure of choice in this situation. Failure of endoscopic therapy has been defined as "further variceal bleeding after two endoscopic treatments during a single hospital admission for an acute bleeding episode". ${ }^{65}$ Used in this situation TIPS leads to immediate cessation of bleeding in $73 \%-96 \%$ of cases. ${ }^{66-69}$

\section{Prevention of rebleeding (box 5)}

PHARMACOLOGICAL AGENTS

$\beta$-Blockers are the most widely used pharmacological agent in the prevention of rebleeding. Numerous trials and three meta-analyses have confirmed the efficacy of $\beta$-blockers over placebo. ${ }^{70-79}$ Overall $\beta$-blockers reduce the risk of rebleeding by about $40 \%$ and mortality by $20 \%{ }^{27}$

\section{ENDOSCOPIC MANAGEMENT}

The benefits of sclerotherapy in preventing rebleeding have been clearly illustrated by a series of well designed randomised controlled trials. Initial trails compared sclerotherapy with no treatment ${ }^{77} 80$ and meta-analysis revealed a significant reduction in rebleeding and improved survival in the groups treated with sclerotherapy. ${ }^{30}$ Subsequent trails have compared sclerotherapy plus $\beta$-blockers with $\beta$-blockers alone. These trials reported a reduced incidence of rebleeding and death in the combined treatment groups ${ }^{81}{ }^{82}$ Pooled results from these two trials reveal the reduction in rebleeding and death to be statistically significant. ${ }^{30}$

There are many published trials comparing variceal ligation with sclerotherapy for the prevention of recurrent variceal bleeding. ${ }^{49} 518384$ A meta-analysis of these studies concludes that treatment with variceal ligation is associated with a reduced risk of rebleeding and an overall improved survival compared with sclerotherapy ${ }^{48}$ Variceal ligation requires fewer sessions to obliterate varices and results in fewer complications compared with sclerotherapy. Follow up from these studies however has been short, generally less than 12 months. More recent evidence suggests that there is a high rate of recurrence of varices in patients treated solely with ligation therapy compared with sclerotherapy. ${ }^{85}$ Ligation therapy followed by sclerotherapy to obliterate small residual varices appears most effective in preventing recurrence of varices and minimising complications. ${ }^{86}$

The conclusions to draw from these endoscopic data are that variceal ligation is superior to sclerotherapy in eradication of varices, due primarily to its lower incidence of side effects. Following successful ligation therapy preliminary evidence suggests that sclerotherapy may be necessary to complete the eradication of small remaining or recurrent varices.

TIPS

Recently TIPS has been compared with sclerotherapy and ligation therapy in the prevention of rebleeding in a number of randomised controlled trials. ${ }^{87-89}$ These trials have varied in design with different endoscopic measures employed, and only three have used $\beta$-blockers with the endoscopic therapy. No trials have compared TIPS with $\beta$-blockers and ligation therapy. Generally the studies have shown reduced rebleeding in the TIPS group, but higher rates of encephalopathy and only one has shown a survival advantage in the TIPS group. ${ }^{89}$ From these data TIPS cannot currently be recommended for the routine prevention of rebleeding.

\section{SURGERY}

Early studies comparing portacaval shunt to non-specific treatment reported greatly reduced rebleeding in the shunt group but significantly higher rates of encephalopathy. ${ }^{90-92}$ Distal splenorenal shunts have also been compared to portacaval shunts but no significant difference in rebleeding was reported in any trial. ${ }^{93}$ Sh Shunt surgery has been compared with sclerotherapy in a meta-analysis and found reduced rates of rebleeding but higher rates of encephalopathy in the shunt group. ${ }^{95}$ Over recent years surgical shunts have received renewed interest due primarily to their effectiveness in preventing rebleeding. Data on surgical shunts performed in recent years indicate better outcomes than earlier reported series. This is primarily due to patient selection, with the majority of procedures performed in Child class A and B patients. ${ }^{96-98}$ Although more recent results of surgical shunts are encouraging, it is premature to suggest that shunt surgery should be recommended in any patient for the indication of prevention of rebleeding. Its present indication lies as rescue therapy in patients in whom TIPS cannot be performed due to portal vein thrombosis or in whom an attempt at TIPS has failed due to technical difficulty.

LIVER TRANSPLANTATION

Liver transplantation is the definitive treatment for patients with advanced liver disease who have bled and should be considered in all such patients. TIPS, unlike surgical shunts, does not seem to compromise subsequent transplant surgery and has been used as bridging therapy to liver transplantation in patients who have bled..$^{99}$ 


\section{Conclusions}

The management of haemorrhage from oesophageal varices has undergone enormous change over recent years. This is due to a combination of the development and implementation of new techniques and pharmaceuticals, in addition to a vast volume of data from randomised trials dealing with management issues in this condition. This has allowed us to make an increasing number of management decisions based on evidence rather than gut feeling.

$\beta$-Blockers have demonstrated efficacy as primary prophylaxis in the prevention of variceal haemorrhage in cirrhotic patients with oesophageal varices. Prophylactic endoscopic therapy, TIPS, or shunt surgery cannot be recommended on current evidence. Treatment of acute variceal bleeding should be aimed at arresting haemorrhage in addition to preventing early rebleeding and thus reducing mortality. Vasoactive drugs control bleeding in up to $90 \%$ of patients. Emergency endoscopic therapy stops bleeding in $90 \%$ of patients. Endoscopic variceal ligation appears equally effective to sclerotherapy and results in less side effects. TIPS is the procedure of choice in patients who fail endoscopic therapy. Both $\beta$-blockers and endoscopic therapy reduce the risk of rebleeding and death. Shunt surgery and TIPS virtually abolish the risk of rebleeding but do so at the cost of precipitating or exacerbating encephalopathy. Liver transplantation should be considered in all patients with advanced liver disease who have bled.

1 Kamath PS, Tyce GM, Miller VM, et al. Endothelin-1 modulates intrahepatic resistance in a rat model of 7 .

2 Rockey DC, Chung JJ. Regulation of inducible nitric oxide synthase and nitric oxide during hepatic injury and fibrogenesis. Am f Physiol 1997;273:G124-30.

3 Maroto A, Gines P, Arroyo V, et al. Brachial and femoral artery blood flow in cirrhosis: relationship to kidney dysfunction. Hepatology 1993; 17:788-93.

4 Christensen E, Fauerholdt L, Schlichting P, et al. Aspects of the natural history of gastrointestinal bleeding in cirrhosis and the effect of prednisone. Gastroenterology 1981;81:944and 52 .

5 D'Amico G, Pasta L, Vizzini GB, et al. Natural history of cirrhosis [abstract]. F Hepatol 1990;13:S22.

6 Cales P, Desmorat H, Vinel JP, et al. Incidence of large oesophageal varices in patients with cirrhosis: application to prophylaxis of first bleeding. Gut 1990;31:1298-302.

7 Prediction of the first variceal hemorrhage in patients with cirrhosis of the liver and esophageal varices. A prospective multicenter study. The North Italian Endoscopic Club for the Study and Treatment of Esophageal Varices. $N$ Engl 7 Med 1988;319:983-9.

8 Gores GJ, Wiesner RH, Dickson ER, et al. Prospective evaluation of esophageal varices in primary biliary cirrhosis: development, natural history, and influence on survival Gastroenterology 1989;96:1552-9.

9 Graham DY, Smith JL. The course of patients after variceal hemorrhage. Gastroenterology 1981;80:800-9.

10 de Dombal FT, Clarke JR, Clamp SE, et al. Prognostic factors in upper GI bleeding. Endoscopy 1986;18:6-10

11 Fugger R, Herbst F, Mirza D, et al. Combined sclerotherapy and operation for the treatment of bleeding oesophageal varices. Eur f Surg 1992;158:485-9.

12 Graffeo M, Buffoli F, Lanzani G, et al. Survival after endoscopic sclerotherapy for esophageal varices in cirrhotics. $\mathrm{Am}$ f Gastroenterol 1994;89:1815-22.

13 Viallet A, Marleau D, Huet M, et al. Hemodynamic evaluation of patients with intrahepatic portal hypertension. Relationship between bleeding varices and the portohepatic gradient. Gastroenterology 1975;69:1297-300.

14 Garcia-Tsao G, Groszmann RJ, Fisher RL, et al. Portal pressure, presence of gastroesophageal varices and variceal pressure, presence of gastroesophage

15 Baker LA, Smith C, Lieberman G. The natural history of esophageal varices. Am f Med 1959;26:228-37.
16 Pagliaro L, D'Amico G, Sorensen TI, et al. Prevention of first bleeding in cirrhosis. A meta-analysis of randomized trials of nonsurgical treatment. Ann Intern Med 1992;117: trials of

17 Beppu K, Inokuchi K, Koyanagi N, et al. Prediction of variceal hemorrhage by esophageal endoscopy. Gastrointest Endosc 1981;27:213-8.

18 Bendtsen F, Henriksen JH, Sorensen TI. Long-term effects of oral propranolol on splanchnic and systemic haemodynamics in patients with cirrhosis and oesophageal varices. Scand 7 Gastroenterol 1991;26:933-9.

19 Pascal JP, Cales P. Propranolol in the prevention of first upper gastrointestinal tract hemorrhage in patients with cirrhosis of the liver and esophageal varices. $N$ Engl f Med 1987;317:856-61.

20 Ideo G, Bellati G, Fesce E, et al. Nadolol can prevent the first gastrointestinal bleeding in cirrhotics: a prospective, randomized study. Hepatology 1988;8:6-9.

21 Lebrec D, Poynard T, Capron JP, et al. Nadolol for prophylaxis of gastrointestinal bleeding in patients with cirrhosis. A randomized trial. F Hepatol 1988;7:118-25.

22 Andreani T, Poupon RE, Balkau BJ, et al. Preventive therapy of first gastrointestinal bleeding in patients with cirrhosis: results of a controlled trial comparing propranolol, endoscopic sclerotherapy and placebo. Hepatology 1990;12: 1413-9.

23 Conn HO, Grace ND, Bosch J, et al. Propranolol in the prevention of the first hemorrhage from esophagogastric varices: a multicenter, randomized clinical trial. The Boston-New Haven-Barcelona Portal Hypertension Study Group. Hepatology 1991;13:902-12.

24 The PROVA Study Group. Prophylaxis of first hemorrhage from esophageal varices by sclerotherapy, propranolol or both in cirrhotic patients: a randomized multicenter trial. both in cirrhotic patients: a
Hepatology 1991;14:1016-24.

25 Propranolol prevents first gastrointestinal bleeding in non-ascitic cirrhotic patients. Final report of a multicenter randomized trial. The Italian Multicenter Project for Propranolol in Prevention of Bleeding. F Hepatol 1989;9:7583.

26 Sieg A, Kommerell B. Primary prevention of hemorrhage of esophageal varices by beta-blockade-generally indicated? Klin Wochenschr 1988;66:1099-101.

27 Hayes PC, Davis JM, Lewis JA, et al. Meta-analysis of value of propranolol in prevention of variceal haemorrhage. Lancet 1990;336:153-6.

28 Poynard T, Cales P, Pasta L, et al. Beta-adrenergicantagonist drugs in the prevention of gastrointestinal bleedantagonist drugs in the prevention of gastrointestinal bleeding in patients with cirrhosis and esophageal varices. An analysis of data and prognostic factors in 589 patients from
four randomized clinical trials. Franco-Italian Multicenter four randomized clinical trials. Franco-Italian

29 Grace ND, Conn HO, Groszmann RJ, et al. Propranolol for prevention of first esophageal variceal hemorrhage (EVH): a lifetime commitment? [abstract]. Hepatology 1990;12:407A.

30 D'Amico G, Pagliaro L, Bosch J. The treatment of portal hypertension: a meta-analytic review. Hepatology 1995;22: 332-54.

31 McCormick P, Burroughs A. Prophylaxis for variceal hemorrhage. Gastrointest Endosc Clin N Am 1992;2:167-82.

32 De BK, Ghoshal UC, Das T, et al. Endoscopic variceal ligation for primary prophylaxis of oesophageal variceal bleed: preliminary report of a randomized controlled trial. $f$ Gastroenterol Hepatol 1999; 14:220-4.

33 Angelico M, Carli L, Piat C, et al. Isosorbide-5-mononitrate versus propranolol in the prevention of first bleeding in cirrhosis. Gastroenterology 1993;104:1460-5.

34 Merkel C, Marin R, Enzo E, et al. Randomised trial of nadolol alone or with isosorbide mononitrate for primary prophylaxis of variceal bleeding in cirrhosis. Lancet 1996; 348:1677-81.

35 Merkel C, Marin R, Sacerdoti D, et al. Long-term results of a clinical trial of nadolol with or without isosorbide mononitrate for primary prophylaxis of variceal bleeding in cirrhosis. Hepatology 2000;31:324-9.

36 Jackson FC, Perrin EB, Smith AG, et al. A clinical investigation of the portacaval shunt. II. Survival analysis of the prophylactic operation. Am $\mathcal{F}$ Surg 1968;115:22-42

37 Resnick RH, Chalmers TC, Ishihara AM, et al. A controlled study of the prophylactic portacaval shunt. A final report. Ann Intern Med 1969;70:675-88.

38 Conn HO, Lindenmuth WW, May CJ, et al. Prophylactic portacaval anastomosis. Medicine (Baltimore) 1972;51:2740.

39 Conn HO, Lindenmuth WW, May CJ, et al. Prophylactic portacaval anastamosis in cirrhotic patients with esophageal varices. N Engl F Med 1965;272:1255-63.

40 Bernard B, Cadranel JF, Valla D, et al. Prognostic significance of bacterial infection in bleeding cirrhotic patients: a prospective study. Gastroenterology 1995;108: $1828-34$.

41 Goulis J, Armonis A, Patch D, et al. Bacterial infection is independently associated with failure to control bleeding in cirrhotic patients with gastrointestinal hemorrhage. Hepatology 1998;27:1207-12

42 Blaise M, Pateron D, Trinchet JC, et al. Systemic antibiotic therapy prevents bacterial infection in cirrhotic patients with gastrointestinal hemorrhage. Hepatology 1994;20:34-8.

43 Bernard B, Grange JD, Khac EN, et al. Antibiotic prophylaxis for the prevention of bacterial infections in cirrhotic patients with gastrointestinal bleeding: a metaanalysis. Hepatology 1999;29:1655-61. 
44 Siringo S, Bolondi L, Piscaglia F, et al. Peptic ulcer in patients with liver cirrhosis: a retrospective endoscopic and

45 Westaby D, Hayes PC, Gimson AE, et al. Controlled clinical trial of injection sclerotherapy for active variceal bleeding. Hepatology 1989;9:274-7.

46 Schuman BM, Beckman JW, Tedesco FJ, et al. Complications of endoscopic injection sclerotherapy: a review. $A m$ f Gastroenterol 1987;82:823-30.

47 Polson RJ, Westaby D, Gimson AE, et al. Sucralfate for the prevention of early rebleeding following injection sclerotherapy for esophageal varices. Hepatology 1989;10:279-82.

48 Laine L, Cook D. Endoscopic ligation compared with sclerotherapy for treatment of esophageal variceal bleeding. A meta-analysis. Ann Intern Med 1995;123:280-7.

49 Stiegmann GV, Goff JS, Michaletz-Onody PA, et al. Endoscopic sclerotherapy as compared with endoscopic ligation for bleeding esophageal varices. N Engl f Med 1992; 326:1527-32.

50 Lo GH, Lai KH, Cheng JS, et al. Emergency banding ligation versus sclerotherapy for the control of active bleeding from esophageal varices. Hepatology 1997;25:1101-4.

51 Hou MC, Lin HC, Kuo BI, et al. Comparison of endoscopic variceal injection sclerotherapy and ligation for the treatment of esophageal variceal hemorrhage: a prospective randomized trial. Hepatology 1995;21:1517-22.

52 Sarin SK, Govil A, Jain AK, et al. Prospective randomized trial of endoscopic sclerotherapy versus variceal band ligation for esophageal varices: influence on gastropathy,
gastric varices and variceal recurrence. $\mathcal{f}$ Hepatol $1997 ; 26$ : 826-32.

53 Levacher S, Letoumelin P, Pateron D, et al. Early administration of terlipressin plus glyceryl trinitrate to con-
trol active upper gastrointestinal bleeding in cirrhotic patients. Lancet 1995;346:865-8.

54 Walker S, Stiehl A, Raedsch R, et al. Terlipressin in bleeding esophageal varices: a placebo-controlled, double-blind esophageal varices: a placebo-c
study. Hepatology 1986;6:112-5.

55 Freeman JG, Cobden I, Record CO. Placebo-controlled trial of terlipressin (glypressin) in the management of acute variceal bleeding. F Clin Gastroenterol 1989;11:58-60.

56 Soderlund C, Magnusson I, Torngren S, et al. Terlipressin (triglycyl-lysine vasopressin) controls acute bleeding oesophageal varices. A double-blind, randomized, placebocontrolled trial. Scand F Gastroenterol 1990;25:622-30.

57 Lee YF, Tsay YT, Lai KH, et al. A randomised controlled trial of triglycyl-vasopressin and vasopressin plus nitroglycerin in the control of acute esophageal variceal hemorrhege. Chin 7 Gastroenterol 1988;5:131-8.

58 Walker S, Kreichgauer HP, Bode JC. Terlipressin vs. somatostatin in bleeding esophageal varices: a controlled, doubletostatin in bleeding esophageal varices: a cont
blind study. Hepatology 1992;15:1023-30.

59 Feu F, Ruiz del Arbol L, Banares R, et al. Double-blind randomized controlled trial comparing terlipressin and somatostatin for acute variceal hemorrhage. Variceal Bleeding Study Group. Gastroenterology 1996;111:1291-9.

60 Jenkins SA, Shields R, Davies M, et al. A multicentre randomised trial comparing octreotide and injection sclerotherapy in the management and outcome of acute variceal haemorrhage. Gut 1997;41:526-33.

61 Chojkier M, Conn HO. Esophageal tamponade in the treatment of bleeding varices. A decadel progress report. Dig Dis Sci $1980 ; 25: 267-72$

62 Hunt PS, Korman MG, Hansky J, et al. An 8-year prospective experience with balloon tamponade in emergency control of bleeding esophageal varices. Dig Dis Sci 1982;27: 413-6.

63 Panes J, Teres J, Bosch J, et al. Efficacy of balloon tamponade in treatment of bleeding gastric and esophageal varices. Results in 151 consecutive episodes. Dig Dis Sci 1988;33: 454-9.

64 Haddock G, Garden OJ, McKee RF, et al. Esophageal tamponade in the management of acute variceal hemorrhage. Dig Dis Sci 1989;34:913-8.

65 Terblanche J, Burroughs AK, Hobbs KE. Controversies in the management of bleeding esophageal varices (2). N Engl f Med 1989;320:1469-75.

66 LaBerge JM, Ring EJ, Gordon RL, et al. Creation of transjugular intrahepatic portosystemic shunts with the wallstent endoprosthesis: results in 100 patients. Radiology 1993;187: 413-20.

67 Azoulay D, Castaing D, Ichai P, et al. Intrahepatic portasystemic shunt as a salvage treatment of uncontrolled hemorrhage caused by rupture of esophageal varices in hemorrhage caused by rupture of esophageal varices
patients with liver cirrhosis. Presse Med 1996;25:842-6.

68 McCormick PA, Dick R, Panagou EB, et al. Emergency transjugular intrahepatic portasystemic stent shunting as salvage treatment for uncontrolled variceal bleeding. $\mathrm{Br} f$ Surg 1994;81:1324-7.

69 Sanyal AJ, Freedman AM, Luketic VA, et al. Transjugular intrahepatic portosystemic shunts for patients with active variceal hemorrhage unresponsive to sclerotherapy. Gastroenterology 1996;111:138-46.

70 Burroughs AK, Jenkins WJ, Sherlock S, et al. Controlled trial of propranolol for the prevention of recurrent variceal hemorrhage in patients with cirrhosis. $N$ Engl 7 Med 1983;309:1539-42.

71 Lebrec D, Poynard T, Bernuau J, et al. A randomized controlled study of propranolol for prevention of recurrent gastrointestinal bleeding in patients with cirrhosis: a final report. Hepatology 1984;4:355-8.

72 Villeneuve JP, Pomier-Layrargues G, Infante-Rivard C, et al. Propranolol for the prevention of recurrent variceal hemorrhage: a controlled trial. Hepatology 1986;6:1239-43.
73 Queuniet AM, Czernichow P, Lerebours E, et al. Controlled study of propranolol in the prevention of recurrent hemorrhage in cirrhotic patients. Gastroenterol Clin Biol 1987;11:41-7.

74 Colombo $\mathrm{M}$, de Franchis R, Tommasini $\mathrm{M}$, et al. Beta-blockade prevents recurrent gastrointestinal bleeding in well-compensated patients with alcoholic cirrhosis: a multicent

75 Sheen IS, Chen TY, Liaw YF. Randomized controlled study of propranolol for prevention of recurrent esophageal
varices bleeding in patients with cirrhosis. Liver 1989;9:1-5.

76 Garden OJ, Mills PR, Birnie GG, et al. Propranolol in the prevention of recurrent variceal hemorrhage in cirrhotic patients. A controlled trial. Gastroenterology 1990;98:18590.

77 Rossi V, Cales P, Burtin P, et al. Prevention of recurrent variceal bleeding in alcoholic cirrhotic patients: prospective controlled trial of propranolol and sclerotherapy. $\mathcal{F}$ Hepatol 1991;12:283-9.

78 Cerbelaud P, Lavignolle A, Perrin D, et al. Propranolol et prevention des recidives de rupture de varice oesophagienne du cirrhotique. Gastroenterol Clin Biol 1986;18:A10.

79 Colman J, Jones P, Finch C, et al. Propranolol in the prevention of variceal hemorrhage in alcholic cirrhotic patients [abstract]. Hepatology 1990;12:851

80 Terblanche J, Bornman PC, Kahn D, et al. Failure of repeated injection sclerotherapy to improve long-term survival after oesophageal variceal bleeding. A five-year prospective controlled clinical trial. Lancet 1983;ii: 1328-32.

81 O'Connor KW, Lehman G, Yune H, et al. Comparison of three nonsurgical treatments for bleeding esophageal varices. Gastroenterology 1989;96:899-906.

82 Ink O, Martin T, Poynard T, et al. Does elective sclerotherapy improve the efficacy of long-term propranolol for prevention of recurrent bleeding in patients with severe cirrhosis? A prospective multicenter, randomized trial. Hepatology 1992;16:912-9.

83 Gimson AE, Ramage JK, Panos MZ, et al. Randomised trial of variceal banding ligation versus injection sclerotherapy for bleeding oesophageal varices. Lancet 1993;342:391-4.

84 Laine L, el-Newihi HM, Migikovsky B, et al. Endoscopic ligation compared with sclerotherapy for the treatment of bleeding esophageal varices. Ann Intern Med 1993;119:1-7.

85 Baroncini D, Milandri GL, Borioni D, et al. prospective randomized trial of sclerotherapy versus ligation in the elective treatment of bleeding esophageal varices. Endoscopy 1997; 29:235-40.

86 Masumoto H, Toyonaga A, Oho K, et al. Ligation plus lowvolume sclerotherapy for high-risk esophageal varices: comparisons with ligation therapy or sclerotherapy alone. I Gastroenterol 1998;33:1-5.

87 Cabrera J, Maynar M, Granados R, et al. Transjugular intrahepatic portosystemic shunt versus sclerotherapy in the elective treatment of variceal hemorrhage. Gastroenterology 1996;110:832-9.

88 Cello JP, Ring EJ, Olcott EW, et al. Endoscopic sclerotherapy compared with percutaneous transjugular intrahepatic portosystemic shunt after initial sclerotherapy in patients with acute variceal hemorrhage. A randomized, controlled trial. Ann Intern Med 1997;126:858-65.

89 Garcia-Villarreal L, Martinez-Lagares F, Sierra A, et al. Transjugular intrahepatic portosystemic shunt versus endoscopic sclerotherapy for the prevention of variceal rebleeding after recent variceal hemorrhage. Hepatology 1999;29: $27-32$.

90 Jackson FC, Perrin EB, Felix WR, et al. A clinical investigation of the portacaval shunt. V. Survival analysis of the therapeutic operation. Ann Surg 1971;174:672-701.

91 Resnick RH, Iber FL, Ishihara AM, et al. A controlled study of the therapeutic portacaval shunt. Gastroenterology 1974; 67:843-57

92 Rueff B, Prandi D, Degos F, et al. A controlled study of therapeutic portacaval shunt in alcoholic cirrhosis. Lancet 1976;i:655-9.

93 Reichle FA, Fahmy WF, Golsorkhi M. Prospective comparative clinical trial with distal splenorenal and mesocaval shunts. Am ₹ Surg 1979;137:13-21.

94 Langer B, Taylor BR, Mackenzie DR, et al. Further report of a prospective randomized trial comparing distal splenorenal shunt with end-to-side portacaval shunt. An analysis of encephalopathy, survival, and quality of life. Gastroenterology 1985;88:424-9.

95 Spina GP, Henderson JM, Rikkers LF, et al. Distal spleno-renal shunt versus endoscopic sclerotherapy in the prevention of variceal rebleeding. A meta-analysis of 4 ranprevention of variceal rebleeding. A meta-analysis of

96 Henderson JM, Gilmore GT, Hooks MA, et al. Selective shunt in the management of variceal bleeding in the era of liver transplantation. Ann Surg 1992;216:248-54.

97 Orloff MJ, Orloff MS, Orloff SL, et al. Three decades of experience with emergency portacaval shunt for acutely bleeding esophageal varices in 400 unselected patients

98 Sarfeh IJ, Rypins EB. Partial versus total portacaval shunt in alcoholic cirrhosis. Results of a prospective, randomized clinical trial. Ann Surg 1994;219:353-61.

99 Ring EJ, Lake JR, Roberts JP, et al. Using transjugular intrahepatic portosystemic shunts to control variceal bleeding before liver transplantation. Ann Intern Med 1992;116:304-9. 